\title{
行列のジョルダン標準形の数值計算法*
}

\author{
大竹 剛 ${ }^{\dagger} \cdot$ 古賀 雅伸
}

\section{A Method for Numerical Computation of Jordan Canonical Form of Matrix*}

Go Ohtake ${ }^{\dagger}$ and Masanobu Koga ${ }^{\ddagger}$ and Mitsuji Sampei ${ }^{\S}$

\begin{abstract}
The Jordan canonical form of a matrix plays an important role in control system theory. But the numerically stable computation method has not been established. In this paper, we propose a numerical algorithm for the computation of Jordan canonical form of matrix. The transformation matrix consists of principal vectors obtained by the intersection of the kernel of the eigen-vector spaces. And we define the numerical Jordan canonical form of matrix and propose a more stable numerical method. The numerical example shows that the proposed method is more reliable than the well-known commercially available software.
\end{abstract}

\section{1.はじめに}

制御対象を同定する場合，対象を離散時間系として扱 うことが多いが, 連続時間系の方が極や零点と応答波形 の関係が離散時間系よりも詳細に把握できるなどの理由 で, 離散時間モデルを連続時間モデルに変換したいこと がある。

離散時間系を連続時間系へ変換する方法は大きく分け て 2 通りある. 一つは行列の対数を数值的に計算する数 值的方法 $[1,2]$, もう一つはシステム行列をジョルダン標 準形に変換して求める解析的方法 $[3-5]$ である. 前者の 方法では, [1] で問題とされた, 重複固有值をもつ行列の 対数関数を正確に計算する方法が [2] で提案されている. 一方, 後者の方法ではジョルダン標準形を数值的に求め

\footnotetext{
* 原稿受付 2001 年 3 月 26 日

$\dagger$ 東京工業大学 大学院 情報理工学研究科 Dept. of Mechanical and Environmental Informatics, Tokyo Institute of Technology; 2-12-1 Oh-Okayama, Meguro-ku, Tokyo 152-8552, JAPAN

‡ 九州工業大学 情報工学部 Dept. of Control Engineering and Science, Kyushu Institute of Technology; 680-4 Kawazu, Iizuka, Fukuoka 820-8502, JAPAN

$\S$ 東京工業大学 大学院 理工学研究科 Dept. of Mechanical and Control Engineering, Tokyo Institute of Technology; 2-12-1 Oh-Okayama, Meguro-ku, Tokyo 1528552, JAPAN
}

Key Words: linear system, system identification, numerical method.
る方法が必要となるが, ジョルダン標準形に関して構造 不安定である行列（付録参照）のジョルダン標準形を数 值的に安定に求めることは難しい [6]. ジョルダン標準形 はこの変換問題に限らず，状態遷移行列や正準形にも用 いられる [7]ことから，これを数值的に求める方法が必 要とされている.

本論文では, まずジョルダン標準形を求める数值計算 に適したアルゴリズムを提案する。つぎに，ジョルダン 標準形を数值的に求める際の問題点について述べる. 構 造的に不安定な行列は, 微少であっても摂動が加わると （次節で説明する）ジョルダン型が変化するので, 丸め 誤差等の数值計算誤差よって変化し得るジョルダン型の 集合を考え，その集合からある評価関数を最小とするも のを最適な数值解とする方法を提案する. 最後に, 数值 例題により本論文で提案する方法の有効性を示す.

\section{2. ジョルダン標準形}

本節では, 後の議論のため行列 $A$ のジョルダン標準形 (Jordan canonical form) の数学的定義を復習し, ジョ ルダン標準形と密接な関係があるジョルダン型につい て述べる. いま, $A$ が代数的重複度 $[8] t_{1}, \ldots, t_{p}$ の固有值 $\lambda_{1}, \ldots, \lambda_{p}$ をもとする.このとき,

$$
\operatorname{det}(z I-A)=\left(z-\lambda_{1}\right)^{t_{1}}\left(z-\lambda_{2}\right)^{t_{2}} \cdots\left(z-\lambda_{p}\right)^{t_{p}}
$$

が成立し，各固有值 $\lambda_{k}$ に対して次式を満たす固有べク トル $u_{k}$ が $s_{k}(\geq 1)$ 個存在する. 


$$
A u_{k}=\lambda_{k} u_{k}
$$

$s_{k}$ は幾何学的重複度 [8] であり, 次式で求めることがで きる。

$$
\operatorname{rank}\left(A-\lambda_{k} I\right)=n-s_{k}
$$

もし，ある固有值 $\lambda$ (添字 $k$ を省略する) に対し $s<t$ ならば，行列 $A$ は対角化不能である：この場合，ある整 数 $\bar{h} \geq 2$ に対し,

$$
\operatorname{rank}\left(\operatorname{Ker}\left((A-\lambda I)^{\bar{h}}\right)\right)=t
$$

となり，方程式

$$
(A-\lambda I)^{l} x_{l}=0, \quad l=1,2, \ldots, \bar{h}
$$

の解が存在する。ただし, $\operatorname{Ker}(M)$ は行列 $M$ のカーネ ル空間を張るべクトルから構成される行列である.ささ にもし,

$$
\begin{aligned}
& (A-\lambda I)^{l} v_{l}=0 \\
& (A-\lambda I)^{l-1} v_{l} \neq 0
\end{aligned}
$$

ならば, (1) 式の解を $A$ の主要べクトル, 特に段階 $l$ の 主要べクトルとよび $v_{l}$ で表す [9]. (1) 式から

$$
(A-\lambda I)^{\bar{h}} v_{l}=(A-\lambda I)^{\bar{h}-l}\left[(A-\lambda I)^{l} \dot{v}_{l}\right]=0
$$

が成り立つので, 段階 $l$ 主要べクトル $v_{l}$ はそれより高 い段階の解でもあり，また最高段階 $の$ の解でもある。し たがって，(1) 式で表される各方程式の解全体は, $l=\bar{h}$ の方程式の一般解に含まれる. ところが， $v_{l}$ を段階 $l$ の 主要ベクトルと仮定すると,

$$
(A-\lambda I)^{l} v_{l}=(A-\lambda I)^{l-\varrho}\left[(A-\lambda I)^{\varrho} v_{l}\right]=0
$$

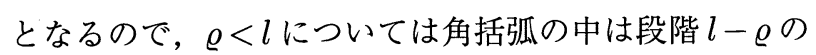
主要ベクトルを表す。すなわち

$$
(A-\lambda I)^{\varrho} v_{l}=v_{l-\varrho} \quad(\varrho<l)
$$

である.これより， $v_{0}=0$ と定義すれば, 特に $\varrho=1 に$ 対して次の重要な関係を得る.

$$
(A-\lambda I) v_{l}=v_{l-1}, \quad l=1,2, \ldots, \bar{h}
$$

したがって，ある固有ベクトル $v_{1}$ に対して主要ベクトル は次の公式から順々に求まる.

$$
\begin{aligned}
& (A-\lambda I) v_{1}=0 \\
& (A-\lambda I) v_{2}=v_{1} \\
& \quad \vdots \\
& (A-\lambda I) v_{h}=v_{h-1}, \quad(1 \leq h \leq \bar{h})
\end{aligned}
$$

(3) 式の関係をもつベクトル列 $v_{1}, \ldots, v_{h}$ を主要ベクトル 鎖 [9] といい, 固有べクトルの数 $s$ と同数の主要べクト ル鎖が存在する。なお, $h$ を主要べクトル鎖の高さ, $v_{h}$
を progenitor とよぶ [8].

さて，添字 $k$ を付けて (3) 式をまとめると，

$$
\begin{aligned}
A T_{k i} & =T_{k i} J_{k i} \\
T_{k i} & =\left[v_{1}, \ldots, v_{h_{i}}\right] \\
J_{k i} & =\left[\begin{array}{ccccc}
\lambda_{k} & 1 & & & \\
& \lambda_{k} & 1 & & 0 \\
& & \ddots & \ddots & \\
& & & \ddots & \\
0 & & & \ddots & 1 \\
& & & & \lambda_{k}
\end{array}\right]
\end{aligned}
$$

となる $\left(J_{k i}\right.$ をジョルダン細胞とよぶ $)$.すべての主要べ クトル鎖をまとめ, 行列 $T_{k}:=\left[T_{k 1}, \ldots, T_{k s_{k}}\right]$ を作る.こ の行列を各固有值 $\lambda_{k}$ に対して求め，これらをまとめて $n \times n$ 行列 $T:=\left[T_{1}, \ldots, T_{p}\right]$ を作ると, $T$ は正則であり,

$$
J=T^{-1} A T=\operatorname{diag}\left(J_{k i}\right) \quad\left(\begin{array}{l}
k=1, \ldots, p \\
i=1, \ldots, s_{k}
\end{array}\right)
$$

を得る. (5) 式が行列 $A$ のジョルダン標準形の数学的定 義である。また (4) 式より, 高さ $h$ の主要べクトル鎖 1 個にh次のジョルダン細胞 1 個が対応することが分かる.

さて $(2)$ 式より, 主要べクトル $v_{l}$ は零空間

$$
N_{l}:=\operatorname{nullspace}(A-\lambda I)^{l}
$$

の成分であり，さらに，

$$
v_{l} \in N_{l}-N_{l-1}
$$

の関係を満たす。ただし $N_{l}-N_{l-1}$ は $N_{l}$ から $N_{l-1}$ を除 いた空間を表す。さらに， $v_{l}$ はそれより高い段階の解で もあり；また $N_{\bar{h}}=N_{\bar{h}+1}=\ldots=\Psi$ であることから，

$$
N_{1} \subset N_{2} \subset \cdots \subset N_{\bar{h}}=\Psi
$$

である. $\bar{h}=3$ の場合における主要べクトル鎖の関係の 例を Fig. 1 に示す.

ここで, $N_{l}$ の次元を $m_{l}:=\operatorname{dim}\left(N_{l}\right)$ と定義すると,

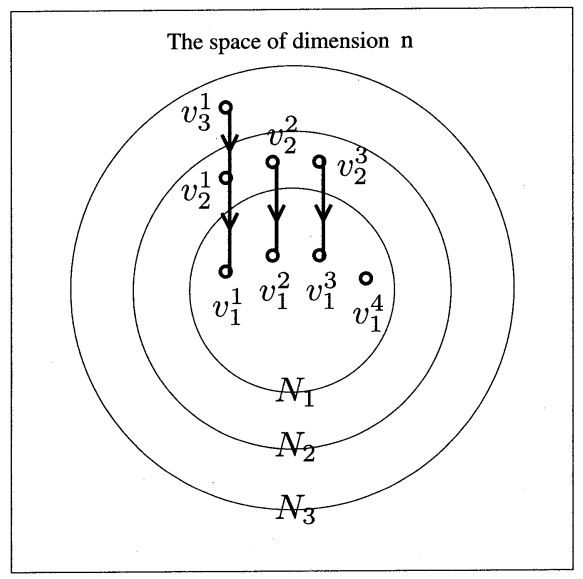

Fig. 1 Arrangement of principal vector chains 


$$
s=m_{1}<m_{2}<\cdots<m_{\bar{h}}=t
$$

となるので, たとえば高さ $l$ 主要べクトル鎖の個数は $\left(m_{l}-m_{l-1}\right)-\left(m_{l+1}-m_{l}\right)$ と求められる.したがって, 固有值 $\lambda$ に対するジョルダン細胞の構造は $\left(m_{1}, \ldots, m_{\bar{h}}\right)$ や，各主要べクトル鎖の高さ $\left(h_{1}, \ldots, h_{s}\right)$ などによって一 意に決まる．これらを相異なる固有值に対してそれぞれ 求めてまとめたものを特性数とよび，これによってジョ ルダン標準形の構造が決定される. 特性数には以下のよ うなものがある $[8,9]$.

- Kågström の特性数 : 零空間 $N_{l}$ の次元の並び $\left.\left[\left(m_{1}, \ldots, m_{\bar{h}_{1}}\right)_{1}, \ldots,\left(m_{1}, \ldots, m_{\bar{h}_{p}}\right)_{p}\right)\right]$

- Segre の特性数 : 主要べクトル鎖の高さの並び $\left[\left(h_{1}, \ldots, h_{s_{1}}\right)_{1}, \ldots,\left(h_{1}, \ldots, h_{s_{p}}\right)_{p}\right]$

- Weyr の特性数 : 各段階の主要べクトルの数の並び $\left[\left(c_{1}, \ldots, c_{\bar{h}_{1}}\right)_{1}, \ldots,\left(c_{1}, \ldots, c_{\bar{h}_{p}}\right)_{p}\right]$

簡単のため, (重複) 固有值が 1 個しか存在しない場合 を考えると，たとえばFig. 1 の場合，それぞれの特性数 はつぎのようになる。

- Kågström の特性数 : $[(4,7,8)]$

- Segre の特性数 : $[(3,2,2,1)]$

- Weyr の特性数 : $[(4,3,1)]$

また，固有值と上で述べた特性数の組をジョルダン型 とよぶ.たとえば, Kågströmの特性数と組み合わせた ジョルダン型は以下のようになる。

$$
\left.\beta=\left[\left(\lambda_{1}, m_{1}, \ldots, m_{\bar{h}_{1}}\right)_{1}, \ldots,\left(\lambda_{p}, m_{1}, \ldots, m_{\bar{h}_{p}}\right)_{p}\right)\right]
$$

（注意 1） $A$ のジョルダン標準形を求めることは，Aの ジョルダン型を求めることに等しく, ジョルダン型 $\beta$ の ジョルダン標準形を $J(\beta)$ と書く.

\section{3. ジョルダン標準形を求めるアルゴリズム}

本節では, 行列 $A$ のジョルダン標準形を求めるアル ゴリズムについて述べる. なお, 行列 $A$ とその固有值 $\lambda_{i}(i=1,2, \ldots, n)$ は与えられるものとする.

ジョルダン標準形を求めるアルゴリズムで問題となる のは，ある固有值 $\lambda$ に対する主要べクトル鎖をどのよう にして求めるか, ということである. すなわち, 代数的 重複度 $t$, 幾何学的重複度 $s$ の固有值 $\lambda$ に対し,

$$
\begin{aligned}
& (A-\lambda I) v_{1}^{1}=0 \quad(A-\lambda I) v_{1}^{s}=0 \\
& (A-\lambda I) v_{2}^{1}=v_{1}^{1} \quad \ldots \quad(A-\lambda I) v_{2}^{s}=v_{1}^{s} \\
& (A-\lambda I) v_{h_{1}}^{1}=v_{h_{1}-1}^{1} \quad(A-\lambda I) v_{h_{s}}^{s}=v_{h_{s}-1}^{s} \\
& \text { と } \\
& h_{1}+\cdots+h_{s}=t
\end{aligned}
$$

を満たす $t$ 個の線形独立なべクトル $v_{1}^{1}, \ldots, v_{h_{1}}^{1}, \ldots, v_{1}^{s}$, $\ldots, v_{h_{s}}^{s}(s$ 個の主要べクトル鎖）をどのようにして求め ればよいかが問題となる。
従来の方法 [10] では, (7) 式の連立方程式を解くこと により主要べクトル鎖を求めているが, 一般に (7) 式を 連立方程式として解くには試行錯誤が伴うため, アルゴ リズム化しにくいという久点があった。また，(8)式を 満たす $h_{1}, \ldots, h_{s}$ の組は一般に多数存在するため, (7) 式 の連立方程式が一意に決まらない, という問題があった。

そこで, 本論文ではこれらの問題点を踏まえ, 以下の アルゴリズムを提案する。

step 1 各固有值が重複しているかいないかを判定し, 各 固有值 $\lambda_{i}$ の代数的重複度 $t_{i}(i=1, \ldots, p)$ を決定する。

※ 以下の step 2 から step 4 までの計算は, 各固有值 $\lambda_{i}$ に関して行う。

step $2 N_{l}$ から $N_{l-1}$ を引いた空間の次元（すなわち段階 lの主要ベクトルの数) $c_{l}$ は, 以下のように求められる.

$$
c_{l}= \begin{cases}n-\operatorname{rank}\left(A-\lambda_{i} I\right) & (l=1) \\ \operatorname{rank}\left(A-\lambda_{i} I\right)^{l-1}-\operatorname{rank}\left(A-\lambda_{i} I\right)^{l} & (l \geq 2)\end{cases}
$$

ただし， $n$ は $A$ の次数である.この計算を $c_{l}$ が 0 になる まで行い，その 1 つ手前を $c_{\bar{h}}$ とする.この計算により， 主要べクトルの最高段階 $\bar{h}$ が求まる（(6) 式を参照).

step $3 N_{l}(l=1,2, \ldots, \bar{h})$ を張る基底べクトルからなる

$$
X_{l}=\left[x_{1}, \ldots, x_{m_{l}}\right]=\operatorname{Ker}\left(A-\lambda_{i} I\right)^{l}
$$

を求める.

step 4 step 3 で求めた $X_{l}$ から, 主要べクトル鎖を作 り, 変換行列 $T_{i}$ を求める.

step $4.1 \bar{h}=1$ のとき

固有べクトルのみなので，そのまま $X_{1}$ を順番に並べ, 変換行列 $T_{i}=\left[X_{1}, \ldots, X_{t_{i}}\right]$ を作る.

step 4.2 $\bar{h} \geq 2$ のとき

step 4.2.1 $N_{\bar{h}}$ から $N_{\bar{h}-1}$ をのぞいた空間 $N_{\bar{h}}-N_{\bar{h}-1}$ を 張る基底べクトルからなる行列 $U_{\bar{h}}$ を求める.

Fig. 2 に示すように, 空間 $N_{\bar{h}}-N_{\bar{h}-1}$ は, $N_{\bar{h}}$ と $N_{\bar{h}-1}$ の (直交) 補空間の交わりであり, その次元は $c_{\bar{h}}$ なので,

$$
X_{\bar{h}} K_{a}=\operatorname{Ker}\left(X_{\bar{h}-1}^{*}\right) K_{b}
$$

を満たす列フルランクな行列 $K_{a} \in C^{m_{\bar{h}} \times c_{\bar{h}}}$ と $K_{b} \in$

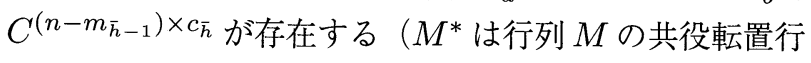
列を表す）。(9)式を変形すると，

$$
\left[X_{\bar{h}},-\operatorname{Ker}\left(X_{\bar{h}-1}^{*}\right)\right]\left[\begin{array}{c}
K_{a} \\
K_{b}
\end{array}\right]=0
$$

となるので, $(9)$ 式を満たす $K_{a}$ と $K_{b}$ は

$$
\left[\begin{array}{l}
K_{a} \\
K_{b}
\end{array}\right]=\operatorname{Ker}\left[X_{\bar{h}},-\operatorname{Ker}\left(X_{\bar{h}-1}^{*}\right)\right]
$$




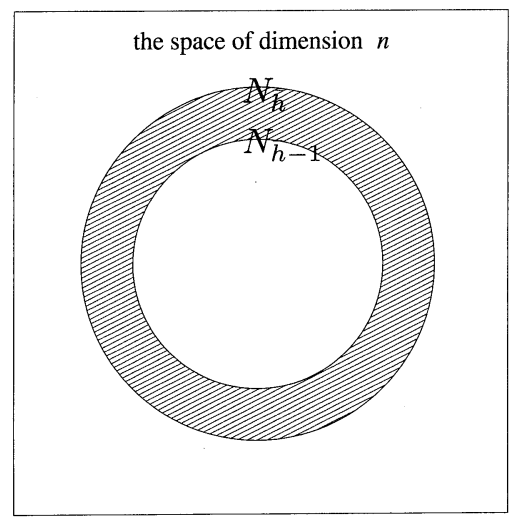

Fig. 2 Intersection between $N_{\bar{h}}$ and complement of $N_{\bar{h}-1}$

で与えられる.よって, 求める行列 $U_{\bar{h}}$ は

$$
U_{\bar{h}}=X_{\bar{h}} K_{a}=\left[v_{\bar{h}}^{1}, v_{\bar{h}}^{2}, \ldots, v_{\bar{h}}^{c_{\bar{h}}}\right]
$$

となる.

step 4.2.2 (3)式より, step 4.2.1で求めた $U_{\bar{h}} に\left(A-\lambda_{i} I\right)$ を次々と掛けることによって, 各段階の主要ベクトルか らなる行列 $U_{1}, U_{2}, \ldots, U_{\bar{h}}$ を求める.

$$
\begin{aligned}
\left(A-\lambda_{i} I\right) U_{\bar{h}} & =U_{\bar{h}-1}=\left[v_{\bar{h}-1}^{1}, v_{\bar{h}-1}^{2}, \ldots, v_{\bar{h}-1}^{c_{\bar{h}}}\right] \\
\left(A-\lambda_{i} I\right) U_{\bar{h}-1} & =U_{\bar{h}-2}=\left[v_{\bar{h}-2}^{1}, v_{\bar{h}-2}^{2}, \ldots, v_{\bar{h}-2}^{c_{\bar{h}}}\right] \\
\ldots & \\
\left(A-\lambda_{i} I\right) U_{2} & =U_{1}=\left[v_{1}^{1}, v_{1}^{2}, \ldots, v_{1}^{c_{\bar{h}}}\right]
\end{aligned}
$$

step 4.2.3 step 4.2 .2 で得られた行列 $U_{1}, U_{2}, \ldots, U_{\bar{h}}$ に 対し，それぞれ $W_{1}:=U_{1}, \ldots, W_{\bar{h}}:=U_{\bar{h}}$ を作る。また， 主要べクトル鎖を順番に並べ, 行列 $V_{\bar{h}}$ を作る。

$$
V_{\bar{h}}=\left[v_{1}^{1}, v_{2}^{1}, \ldots, v_{\bar{h}}^{1}, \ldots, v_{1}^{c_{\bar{h}}}, v_{2}^{c_{\bar{h}}}, \ldots, v_{\bar{h}}^{c_{\bar{h}}}\right]
$$

同様にして, step 4.2.1 から step 4.2.3 までの計算 を $k=\bar{h}-1, \bar{h}-2, \ldots, 2$ と降べきの順に行うことにより, 高さ $k$ の主要べクトル鎖を求め, 順番に並べて $V_{k}$ を 作る。このとき, step 4.2.1において, すでに求めた主 要べクトル鎖を形成するべクトルを除くため，(9) 式 に゙おいて $\operatorname{Ker}\left(X_{k-1}^{*}\right)$ の代わりに $\operatorname{Ker}\left(\left[X_{k-1}, W_{k}\right]^{*}\right)$ を 用いる。また step 4.2.3に抏いて， $W_{1}:=\left[W_{1} U_{1}\right], \ldots$, $W_{k}:=\left[W_{k} U_{k}\right]$ とする.

step 4.2.4これまでに求めた $W_{1}$ の列ベクトルの個数が $c_{1}$ よりも小さいならば，それらのべクトルと独立するよ うに残りの主要ベクトル（固有ベクトル）を選ぶ.すな わち,

$$
U_{1}=\operatorname{Ker}\left[\begin{array}{c}
A-\lambda I \\
W_{1}^{*}
\end{array}\right]
$$

を求め, $V_{1}=U_{1}$ とする. 以上ですべての主要べクト 儿鎖が求まった. $V_{1}, \ldots, V_{\bar{h}}$ を並べると, 変換行列 $T_{i}=$ $\left[V_{1}, \ldots, V_{\bar{h}}\right]$ が求まる。 step 5 各固有值に対応する変換行列 $T_{i}$ をまとめて, 変 換行列 $T=\left[T_{1}, \ldots, T_{p}\right]$ が求まる.

（注意 2）従来の方法 [10] では, 最初に固有ベクトル に着目し, 固有べクトルのパラメトリゼーションによっ て (7) 式の連立方程式を試行錯誤的に解いていた。 それ に対し本論文のアルゴリズムは, 最初に progenitor を空 間の交わりという観点から求め, それに $(A-\lambda I)$ を次々 と掛けていくというシステマティックな方法であり, 従 来の試行錯誤的な要素がない. したがって, ジョルダン 標準形を数值的に求めるのに適したアルゴリズムである.

(注意 3) Step 4.2.1に抢いて, $N_{\bar{h}}$ と $N_{\bar{h}-1}$ の補空間 の交わりを求める際に $N_{\bar{h}-1}$ の直交補空間をとっている 理由は，アルゴリズムを簡単化するためである.

（注意 4) Step 4.2.4が必要な理由は, 高さ 1 の主要べ クトル鎖が存在する場合，空間の交わりを用いたStep 4.2.1の方法では求められないからである.

（注意 5）本アルゴリズムは，ほとんどの演算で特異 值分解を利用する。特異值分解は基本的にユニタリ行列 の演算で済ませることができ, 信頼性の高いアルゴリズ ムが存在する [11].

\section{1 例題}

固有值 $\lambda$ に対する主要べクトルが Fig. 1 のような配置 になっている場合, 本論文のアルゴリズムを適用すると 次のような手順になる.

まず, 高さ $\bar{h}=3$ の主要べクトル鎖の progenitor $v_{3}^{1}$ を 求め, $(10)$ 式より $v_{2}^{1}, v_{1}^{1}$ を求めて 1 個目の主要べクト ル鎖 $v_{1}^{1}, v_{2}^{1}, v_{3}^{1}$ が得られる.つぎに高さ $h=2$ の主要べ クトル鎖の progenitor $v_{2}^{2}, v_{2}^{3}$ を求め, (10) 式より $v_{1}^{2}$, $v_{1}^{3}$ を求めて 2 個目の主要べクトル鎖 $v_{1}^{2}, v_{2}^{2}$ と 3 個目の 主要べクトル鎖 $v_{1}^{3}, v_{2}^{3}$ が得られる. 最後に, 残りの固 有べクトルを $v_{1}^{1}, v_{1}^{2}, v_{1}^{3}$ に直交するように選び， 4 個目 の主要ベクトル鎖 $v_{1}^{4}$ が得られる.

\section{4. 数值的ジョルダン標準形}

3.では, 数学的に定義されたジョルダン標準形を求め るアルゴリズムを提案した。しかし，このアルゴリズム を適用するためには数值計算上いくつかの問題点が残さ れている. 本節ではそれらの問題点について述べるとと もに, 数值計算孛考慮した「数值的ジョルダン標準形」 を定義し, ジョルダン標準形を数值的に求める方法を提 案する。

\section{1 ジョルダン標準形を数值的に求めるのが困}

\section{難な理由}

行列 $A$ のジョルダン標準形の中に 2 次以上のジョルダ ン細胞が含まれているならば, 行列 $A$ は重複固有值をも つ. 数学的には固有值が重複しているかいないかははっ きり区別がつくが，この判定を計算機で行うのは非常に 困難である。なぜなら, 行列 $A$ を計算機上で表現したと き, 行列 $A$ はすでに正しく表現されておらず, 計算の段 
階で一般に丸め誤差が含まれるからである。

たとえば, $r$ 次のジョルダン細胞 $J_{r}\left(\lambda_{i}\right)$ に小さな摂動 が入ったときの影響を考える.すなわち， $J_{r}\left(\lambda_{i}\right)$ の $(r, 1)$ 成分に（本来は 0 であるが） $\delta$ の摂動が入ったと仮定す ると, ジョルダン細胞 $J_{r}\left(\lambda_{i}\right)$ が

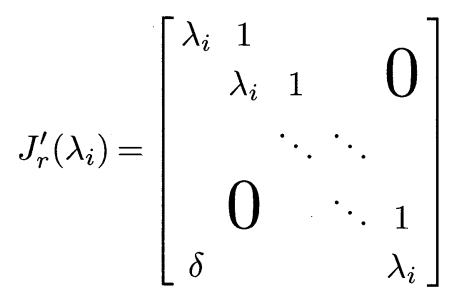

に変わる。その結果, 特性方程式は

$$
\left(\lambda-\lambda_{i}\right)^{r}=(-1)^{r} \delta
$$

となり, $r$ 個の重複固有値 $\lambda_{i}$ は $r$ 個の相異なる固有値

$$
\begin{array}{r}
\lambda_{i}-\delta^{1 / r}(\cos (2 s \pi / r)+\sin (\cos (2 s \pi / r)) \\
(s=0,1, \ldots, r-1)
\end{array}
$$

に変わる.ここで, $\lambda_{i}$ を $O(1)$ とし $, r=10, \delta=10^{-10}$ と 仮定すると，(11) 式より $\lambda_{i}$ に対する $\delta$ 影響が $O\left(10^{-1}\right)$ であることが分かり，もはやそれらの固有值が重複して いるとはいえない [12].

このように, 計算機で求められた固有値からその重複 度を求める場合は, 与えられた $A$ が本当に重複固有值を 持っているとしても, それらが重複していると判定する のは難しい. $A$ が高次のジョルダン細胞をもつときはこ の判定はさらに困難になる．なぜなら，rが大きくなる と (11) 式より $\lambda_{i}$ に対する $\delta$ 影響が大きくなるからで ある。

また，ジョルダン標準形を数值的に求めるのが困難 であるもう一つの理由は, 計算過程で用いる, 行列の rank と Kernel の計算にある.一般に, 行列 $A$ の rank と Kernel を計算するには, 行列 $A$ を次のように特異值 分解する $(U, V$ はユニタリ行列 $)$.

$$
A=U \Lambda V, \quad \Lambda=\left[\begin{array}{ccccc}
\sigma_{1} & & & & \\
& \ddots & & & \\
& & \sigma_{i} & & \\
& & & \ddots & \\
0 & & & & \\
& & & & \\
& & &
\end{array}\right]
$$

ここで, $\sigma_{1} \geq \cdots \geq \sigma_{n}$ は $A$ の特異值である. $\operatorname{rank}(A)$

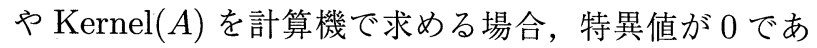
るかどうかの判定を行う必要があり, この判定によって $\operatorname{rank}(A)$ や $\operatorname{Kernel}(A)$ の值が変わる.

以上の問題点を踏まえると, ジョルダン標準形を数 值的に求めるには, 以下に示す二つのパラメー夕 $\varepsilon_{1}$, $\varepsilon_{2}(>0)$ を決定する必要がある.

- $\varepsilon_{1}$ : 固有值の重複度を判定するパラメータ $(2 \leq i \leq n)$ $\left|\lambda_{i}-\lambda_{i-1}\right|<\varepsilon_{1} \Rightarrow \lambda_{i}, \lambda_{i-1}:$ 重複固有值

$\left|\lambda_{i}-\lambda_{i-1}\right| \geq \varepsilon_{1} \Rightarrow \lambda_{i}, \lambda_{i-1}:$ 相異固有值

- $\varepsilon_{2}$ : 行列 $A$ の rank を決定するパラメータ

$$
\begin{array}{cc}
\sigma_{i}<\varepsilon_{2} \Rightarrow \sigma_{j}=0 & (i \leq j \leq n) \\
\sigma_{i} \geq \varepsilon_{2} \Rightarrow \sigma_{j} \neq 0 & (1 \leq j \leq i)
\end{array}
$$

ここで, $\lambda_{i}, \lambda_{i-1}$ は $A$ の固有值, $\sigma_{i}$ は $A$ の特異值で ある。

\section{2 数值的ジョルダン標準形の定義}

ジョルダン型 $\beta$ をつ $A$ のジョルダン標準形を計算 機によって数值的に求める問題を考える.ジョルダン型 $\beta$ をもつ行列の集合を $M_{\beta}$ とする. 2. より，解析的には $A \in M_{\beta}$ が成り立つはずであるが，4.1で述べたように， 一般に $A \in M_{\beta}$ かどうかを数值的に決定するのは困難で ある. そこで, $A \in M_{\beta}$ かどうかを判定する代わりに，あ る $\epsilon>0$ に対して

$$
\begin{aligned}
A & \in M_{\beta}(\epsilon) \\
M_{\beta}(\epsilon) & =\left\{X:\|X-Y\| /\|X\|<\epsilon, Y \in M_{\beta}\right\}
\end{aligned}
$$

が成り立つか調べる.さらに，もし異なるジョルダン型 $\beta^{\prime}(\neq \beta)$ と十分大きな值 $\epsilon^{\prime}(\gg \epsilon)$ に対して

$$
A \notin M_{\beta^{\prime}}\left(\epsilon^{\prime}\right)
$$

ならば，数值的な意味で $A$ が $M_{\beta}$ に属していると判定す る.すなわち $A$ のジョルダン標準形を求める代わりに $A$ のジョルダン型 $\beta$ を数值的に求め, $J(\beta)$ を $A$ の数值的 ジョルダン標準形と定義する [8]. そして以下を満たす正 則な行列 $T$ を変換行列とする.

$$
\left\|T J(\beta) T^{-1}-A\right\|<\epsilon\|A\|
$$

\section{3 数值的ジョルダン標準形の探索法}

4.2 では, すべてのジョルダン型に対して (12) 式を評 価することになっているが，ジョルダン型が変化する主 な理由は 4.1 で述べた $\varepsilon_{1}, \varepsilon_{2}$ の選び方なので, ジョルダ ン型の空間を $\varepsilon_{1}, \varepsilon_{2}$ でパラメトリゼーションし, 最適な ジョルダン標準形を探すことを考える。すなわち，ジョ ルダン型 $\beta$ のう, 評価関数

$$
L:=\left\|T(\beta) J(\beta) T^{-1}(\beta)-A\right\|
$$

を最小にするジョルダン型

$$
\beta_{\mathrm{opt}}=\arg \min _{\beta\left(\varepsilon_{1}, \varepsilon_{2}\right)}\left\|T(\beta) J(\beta) T^{-1}(\beta)-A\right\|
$$

を探す.そして, $J\left(\beta_{\mathrm{opt}}\right)$ を $A$ の数值的ジョルダン標準 形とする。ここで $T(\beta)$ は正則な変換行列である．また， 評価関数が 0 のとき, 数值的ジョルダン標準形は解析的 ジョルダン標準形と一致する。ただし，実際にはすべて の $\varepsilon_{1}, \varepsilon_{2}$ に関して最適なジョルダン標準形を探すことは 不可能なので, たとえば $\varepsilon_{1}$ と $\varepsilon_{2}$ の区間を 


$$
\begin{gathered}
\|A\| m e p \leq \varepsilon_{1}<\|A\| \\
\min _{i}\left(\left\|A-\lambda_{i} I\right\|\right) m e p \leq \varepsilon_{2}<\max _{i}\left(\left\|A-\lambda_{i} I\right\|\right)
\end{gathered}
$$

のように定め，適当なきざみ幅で探す。ただし， mep は 計算機イプシロン（machine epsilon）であり，使用する 計算機に対応して浮動小数点数の精度を特徴づける [13].

（注意 6）参考文献 [8]は，(12) 式を評価せず，(13)式 のみを評価する方法である。 それに対し，本論文で提案 する方法は (12) 式と (13) 式の両方を評価するので, 4.2 で述べた数值的ジョルダン標準形の定義に近い.

\section{5. 数值例題}

【例題 1】次の行列の数值的ジョルダン標準形を提案 方法により求める.

$$
A=\left[\begin{array}{rrr}
0 & 1 & 0 \\
0 & 0 & 1 \\
-2 & -5 & -4
\end{array}\right]
$$

$A$ の数值的ジョルダン標準形 $J$ と, 変換行列 $T$ は

$$
J=\left[\begin{array}{rrr}
-2 & 0 & 0 \\
0 & -1 & 1 \\
0 & 0 & -1
\end{array}\right], \quad T=\left[\begin{array}{rrr}
-0.22 & -0.50 & -0.50 \\
0.44 & 0.50 & -0.00 \\
-0.87 & -0.50 & 0.50
\end{array}\right]
$$

となる.このとき, $L=9.25 \times 10^{-15}, \varepsilon_{1}=1.52 \times 10^{-7}$, $\varepsilon_{2}=1.44 \times 10^{-14}$ である.

パラメー夕 $\varepsilon_{1}, \varepsilon_{2}$ に対する評価関数 $L$ のグラフを Fig. 3 に示す. 図中, 横軸はそれぞれ $\varepsilon_{1}, \varepsilon_{2}$ の対数を とったものであり，縦軸は見やすいように， $L$ の対数を とってさらに一定值を加えてある. Fig. 3 に見られる高 さの異なる三つの領域のうち，Lがもっとも小さな值を とる領域で数值的ジョルダン標準形が求まる.

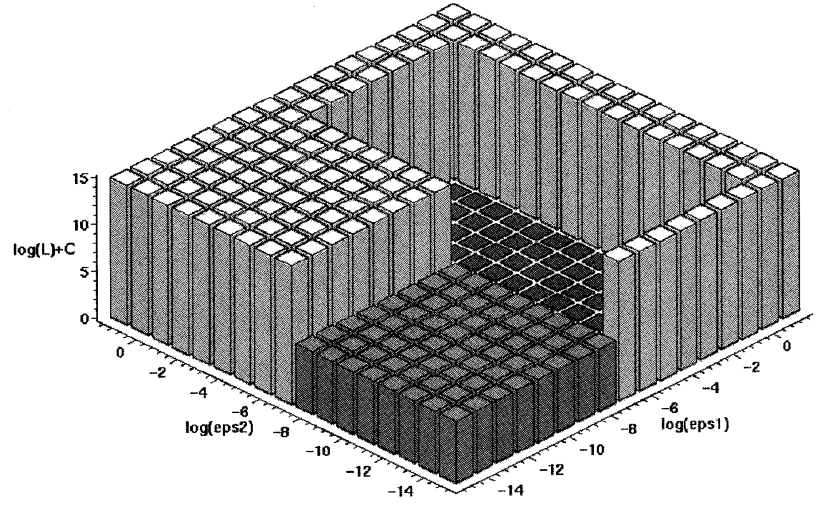

Fig. 3 Value of performance index $L$ to $\left(\varepsilon_{1}, \varepsilon_{2}\right)$

\section{【例題 2】数式処理ソフトウェアとの比較}

次の行列のジョルダン標準形を求める問題を考える. この行列は, 6 次のジョルダン細胞の $(6,1)$ 成分に捸動 $\delta$ が入った場合である。

$$
A=\left[\begin{array}{llllll}
2 & 1 & 0 & 0 & 0 & 0 \\
0 & 2 & 1 & 0 & 0 & 0 \\
0 & 0 & 2 & 1 & 0 & 0 \\
0 & 0 & 0 & 2 & 1 & 0 \\
0 & 0 & 0 & 0 & 2 & 1 \\
\delta & 0 & 0 & 0 & 0 & 2
\end{array}\right]
$$

$\delta$ を変化させたときの評価関数 $L$ の值およびジョルダ ン標準形の構造について, 本論文の提案方法, Matlabの Jordan 関数 [14], Mathematica の JordanDecomposition 関数 [15] を比較した結果を Table 1 に示す.ただし， $\max (\cdot)$ は絶対值が最大である行列成分の大きさを意味す る. Matlab の Jordan 関数は Symbolic Math Toolbox に含まれ, Maple [16]の計算エンジンを使用している. Maple と Mathematica のドキュメントにはジョルダン 標準形を求めるアルゴリズムに関して詳しい記述がない ので，具体的な計算手法は不明である.

Table 1 Value of $\max \left(T J T^{-1}-A\right)$

\begin{tabular}{|c|l|l|l|}
\hline$\delta$ & 提案方法 & Matlab & Mathematica \\
\hline $10^{-10}$ & $1.5 \times 10^{-8}$ & $1.5 \times 10^{-8}$ & $2.3 \times 10^{-10}$ \\
\hline $10^{-20}$ & $2.8 \times 10^{-3}$ & 2.0 & 2.0 \\
\hline $10^{-30}$ & $6.0 \times 10^{-5}$ & $1.1 \times 10^{9}$ & $6.3 \times 10^{-2}$ \\
\hline $10^{-40}$ & $1.3 \times 10^{-6}$ & $2.9 \times 10^{17}$ & $1.4 \times 10^{17}$ \\
\hline
\end{tabular}

参考文献 [6]によると, この行列は摂動 $\delta$ に対して構 造安定であるので， $\delta$ が十分に小さければ， $\delta=0$ と同 じジョルダン標準形が解となる。しかし, Matlab 执よ

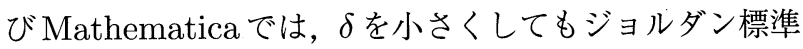
形は対角化されてしまう. それに対し，提案方法では， $\delta=10^{-10}$ では対角化されてしまうが， $\delta \leq 10^{-20}$ では 1 次のジョルダン細胞が形成される.ささらに, 提案方法で は， $\delta$ をさくすると評価関数 $L$ の值は 0 に近づくが, Matlab と Mathematicaでは, 摂動 $\delta$ が小くても， $L$ は非常に大きな值になる．したがって，本論文で提案す る方法は, 他の二つの方法より優れていると考えられる.

\section{6. おわりに}

本論文では, 行列のジョルダン標準形を数值的に求め る方法を提案しだ：な扔，今回提案した方法で行列の ジョルダン標準形を求めれば, 参考文献 [5]の方法で離散 時間系から連続時間系へ変換できることがわかっている.

\section{参考文献}

[1] The Math Works, Inc.: Control System Toolbox User's Guide, The Math Works, Inc. (1992)

[2] 古賀, 大竹, 三平：離散時間系から連続時間系への変換 のための数值計算法; 第 28 回制御理論シンポジウム資 料, pp. 211-214 (1999)

[3] 美多，海津 : 多入出力離散時間系から連続時間系への逆 変換問題; 電気学会論文誌 C, Vol. 104, No. 11, p. 273 
(1984)

[4] 舟橋, 伊藤：離散時間モデルから連続時間モデルへの変 換；第 8 回 SICE D. S. T. シンポジウム資料, p. 159 (1985)

[5] 古賀, A. Lugito：負の実極を持つ離散時間系の連続 時間最小実現; 第 27 回制御理論シンポジウム資料, pp. 237-240 (1998)

[6] 韓, 伊理：ジョルダン標準形, 東京大学出版会 (1982)

[7] 須田：線形システム理論, システム制御情報ライブラ リー 7, 朝倉書店 (1993)

[8] B. Kågström and A. Ruhe: An algorithm for numerical computation of the Jordan normal form of a complex matrix; ACM transactions on mathematical software, Vol. 6, pp. 398-419 (1980)

[9] R. Zurmuehl, 瀬川, 高市：マトリクスの理論と応用, pp. 225-252, ブレイン図書出版 (1972)

[10] 小郷，美多：システム制御理論入門，実教出版（1979）

[11] G. H. Golub and C. F. Van Loan: Matrix Computations, The Johns Hopkins University Press, 2 edition (1989)

[12] G. H. Golub and J. H. Wilkinson: Ill-conditioned eigensystems and the computation of the Jordan canonical form; SIAM Review, Vol. 18, pp. 578-619 (1976)

[13] C. B. Moler, G. E. Forsythe and M. A. Malcom : 計 算機のための数值計算法, 科学技術出版社 (1978)

[14] The Math Works, Inc.: Symbolic Math Toolbox ユー ザーズガイド, The Math Works, Inc. (1993)

[15] S. Wolfram: The Mathematica Book, Cambridge University Press, 3 edition (1996)

[16] A. Heck: Introduction to Maple, Springer Verlag (1993)

\section{付 録}

付録 1. ジョルダン標準形の構造安定性

$A, F$ を $n$ 次の定数行列, $\rho>0$ を十分小さな正数とす るとき, $A+\epsilon F$ のジョルダン型が $|\epsilon| \leq \rho$ の範囲のすべ
ての $\epsilon$ に対して $A$ のジョルダン型と一致するならば， $A$ のジョルダン標準形は摂動 $\epsilon F$ に対して構造安定である といい，そうでないならば構造不安定であるという [6]. 